\title{
M3, a natural lignan xyloside, exhibits potent anticancer activity in HCT116 cells
}

\author{
WEIDONG SHEN ${ }^{1}$, YU ZHAO ${ }^{2}$, HAIJIAO $\mathrm{CHEN}^{3}$, TING ZHANG ${ }^{3}$, SHENBAO WU $^{4}$ and PENGFEI LIU ${ }^{1}$ \\ ${ }^{1}$ Department of Gastroenterology, The Affiliated Jiangyin Hospital of Nantong University, Jiangyin, Jiangsu 214400; \\ ${ }^{2}$ School of Pharmacy, Nantong University, Nantong, Jiangsu 226019; ${ }^{3}$ Department of Center Laboratory, \\ The Affiliated Jiangyin Hospital of Nantong University, Jiangyin, Jiangsu 214400; ${ }^{4}$ Department of Gastroenterology, \\ The Affiliated Yiwu Hospital of Wenzhou Medical College, Yiwu, Zhejiang 322000, P.R. China
}

Received January 18, 2018; Accepted October 12, 2018

DOI: $10.3892 / \mathrm{ol} .2018 .9823$

\begin{abstract}
O-(2',3',4'-tri-O-methyl- $\beta$-D-xylopyranosyl) diphyllin (M3) is a cytotoxic compound that was first isolated from the aerial parts of Phyllanthus taxodiifolius. The current study demonstrated that M3, a lignan xyloside, exhibits anticancer effects in a number of cancer cell lines by MTT test, including HCT116 cells. An association was identified between M3 treatment and the reduced proliferation of cancer cells; the half maximal inhibitory concentration $\left(\mathrm{IC}_{50}\right)$ value of M3 ranged from 0.08 to $1.12 \mu \mathrm{M}$. Furthermore, M3 was revealed to exhibit a stronger antiproliferative effect by Annexin-V-FLUOS test compared with VP-16, another natural lignan used in cancer treatment. Notably, the $\mathrm{IC}_{50}$ value of M3 with MTT test in HCT116 cells was $0.08 \mu \mathrm{M}$. In addition, it was revealed that M3 could induce apoptosis in HCT116 cells in a caspase-3-dependent manner at a lower concentration compared with VP-16. Further analysis identified that the antiproliferation effect of M3 was associated with the promotion of microtubule depolymerization by CytoDYNAMIX Screen 03 Tubulin Polymerization assay. In summary, the current study demonstrated that M3 could inhibit proliferation and induce apoptosis in HCT116 cells, which supports a potential therapeutic application of M3 in cancer treatment, particularly in colon cancer.
\end{abstract}

Correspondence to: $\mathrm{Dr}$ Shenbao $\mathrm{Wu}$, Department of Gastroenterology, The Affiliated Yiwu Hospital of Wenzhou Medical College, 699 Jiangdong Road, Yiwu, Zhejiang 322000, P.R. China

E-mail: wushenbo100@163.com

Dr Pengfei Liu, Department of Gastroenterology, The Affiliated Jiangyin Hospital of Nantong University, 163 Shoushan Road, Jiangyin, Jiangsu 214400, P.R. China

E-mail: shenwd1976@163.com

Key words: lignan xyloside, antiproliferation, pro-apoptosis, microtubule, mechanism

\section{Introduction}

Glycosylated natural products contain sugar attachments that are essential for their biological activities (1). The attached sugars can influence the shape or the physical properties of a molecule and significantly affect the biological activity $(2,3)$. A number of studies have investigated the development of novel glycosylated compounds.

Lignans, particularly arylnaphthalene lignans, including podophyllotoxin, have widely been used in the design and synthesis of anticancer drugs, and the structure-activity associations of these molecules have been extensively studied (4-6). Diphyllin, an arylnaphthalene lignan lactone that is isolated from numerous traditional medicinal plants, has been identified to possess numerous anticancer and antiviral activities (5-7). Diphyllin exhibits tumoricidal effects similar to those of VP-16, with $\mathrm{IC}_{50}$ values ranging from $10^{-6}$ to $10^{-4} \mathrm{M}(8)$. VP-16, another type of natural lignan, has been used clinically in cancer treatment; however, side effects include toxic bone marrow arrest and neurotoxicity (6). Previous studies have identified that glycans serve a crucial role in determining the specificity and potency of arylnaphthalene lignans, including diphyllin, against tumor cells (7-9). In a previous study, we synthesized two cytotoxic diphyllin glycosides, cleistanthin-A and cleistanthoside-A tetraacetate, which are vacuolar $\mathrm{H}^{+}$-ATPase inhibitors (9) that exhibit a higher cytotoxic activity in HCT116 and HepG2 cells compared with diphyllin $(3,4)$.

Certain diphyllin glycosides exhibit inhibitory effects on cancer cell proliferation and on DNA topoisomerase II $(4,10,11)$. However, the inhibition of DNA topoisomerase II activity was not identified to be associated with the inhibition of proliferation, which promoted studies to investigate the mode of action of diphyllin glycosides $(3,11)$. Previous studies have demonstrated that podophyllotoxin compounds, including VP-16, can inhibit the formation of microtubules $(12,13)$. Microtubule polymerization and depolymerization kinetics are required for cell mitosis (4). Instead of performing plant extraction, the current study synthesized the lignan xyloside 4-O-(2',3',4'-tri-O-methyl- $\beta$-D-xylopyranosyl) diphyllin (M3) in sufficient quantities for subsequent experiments. VP-16 is a lignan-containing glucose structure, while M3 is a naphthyl lignan with a xylose structure $(3,12)$. We hypothesized that 
M3, with the additional sugar attachments, exhibits stronger antitumor effects compared with VP-16, acting through the inhibition of the proliferation of tumor cells and promoting tumor cell apoptosis through the inhibition of microtubule formation.

\section{Materials and methods}

Drugs and reagents. The compound M3 (Fig. 1A) was synthesized and the structure was confirmed as described previously (9,10). VP-16, the control drug (Fig. 1B), was obtained from Sigma-Aldrich; Merck KGaA (Darmstadt, Germany). VP-16 and M3 were dissolved in dimethylsulfoxide (DMSO) and the final DMSO concentration did not exceed $0.1 \%$. Sulforhodamine-B, colchicine and anti- $\alpha$-tubulin monoclonal antibody (dilution, 1:100; cat. no. MFCD00145921) were also all purchased from Sigma-Aldrich (Merck KGaA). Alexa Fluor 555-conjugated secondary antibodies were obtained from Invitrogen; Thermo Fisher Scientific, Inc. (Waltham, MA, USA).

Cell lines and cell culture. All cell lines used in the current study (A549, HCT116, HepG2, RM, BCJ-4T, 293T and NCM460) were obtained from the Cell Bank of Type Culture Collection of the Chinese Academy of Sciences (Shanghai, China). The HepG2 cell line was originally considered to be derived from a hepatocellular carcinoma cell line; however, it has since been identified to originate from a hepatoblastoma (14). All cells were cultured in Dulbecco's modified Eagle's medium (DMEM) with $10 \%$ fetal bovine serum (both Gibco; Thermo Fisher Scientific, Inc.) and maintained at $37^{\circ} \mathrm{C}$ in a humidified $5 \% \mathrm{CO}_{2}$ incubator. The cell lines were maintained according to the supplier's protocols. Cell culture media with $0.1 \%$ DMSO was used as a vehicle control for the in vitro experiments.

MTT assay. All cell lines were plated in 96-well plates at a density of $1 \times 10^{3}$ cells/well and cultured overnight at $37^{\circ} \mathrm{C}$. Cells were then cultured with different concentrations $(0.1,1,10$, $100 \mu \mathrm{M}$ ) of reagents, $\mathrm{M} 3$ or VP16, for $72 \mathrm{~h}$ at $37^{\circ} \mathrm{C}$ with $5 \% \mathrm{CO}_{2}$. Next, $11 \mu$ l MTT (5 mg/ml; Nanjing KeyGen Biotech Co., Ltd., Nanjing, China) was added to each well, with a final concentration of $\sim 0.5 \mathrm{mg} / \mathrm{ml}$, and the cells were cultured for $4 \mathrm{~h}$ at $37^{\circ} \mathrm{C}$ in a $5 \% \mathrm{CO}_{2}$ atmosphere. The purple formazan was dissolved by the addition of $10 \%$ sodium dodecyl sulfate and the absorbance was read at $570 \mathrm{~nm}$ using a microplate reader. The half maximal inhibitory concentration $\left(\mathrm{IC}_{50}\right)$ values were then calculated.

Cell morphology and apoptosis analysis. HCT116 cells were plated in 24-well plates at a density of $1 \times 10^{4}$ cells/well and cultured for $24 \mathrm{~h}$ at $37^{\circ} \mathrm{C}$. Cells were then treated with different concentrations of reagents and cultured at $37^{\circ} \mathrm{C}$ in a humidified incubator containing $5 \% \mathrm{CO}_{2}$ for $48 \mathrm{~h}$. Subsequently, $300 \mu \mathrm{l}$ of $5 \mu \mathrm{g} / \mathrm{ml}$ Hoechst 33342 solution (Beijing Solarbio Science and Technology Co., Ltd., Beijing, China) was added to each well and the cells were stained in the dark for $10 \mathrm{~min}$ at $37^{\circ} \mathrm{C}$. The morphology of the cells was observed and images were captured using a fluorescence microscope (magnification, $\mathrm{x} 400$ ).

Following treatment for $72 \mathrm{~h}$ with different concentrations of reagents $(0.03,0.06,0.12,0.25 \mu \mathrm{M} \mathrm{M} 3)$ at $37^{\circ} \mathrm{C}$, apoptosis was analyzed using the Annexin-V-FLUOS Staining kit (Roche Diagnostics, Basel, Switzerland). Briefly, the cells

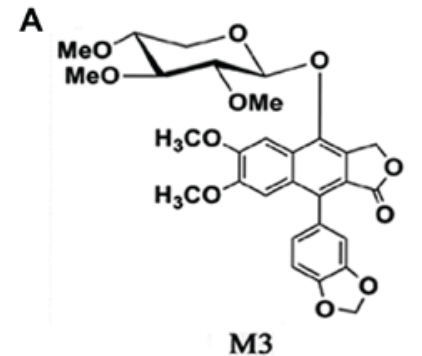

B

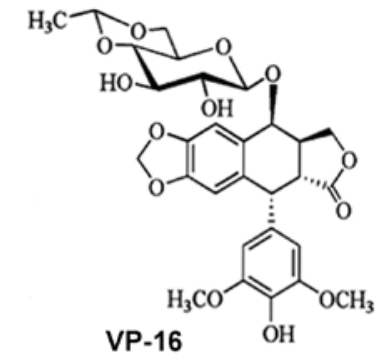

C

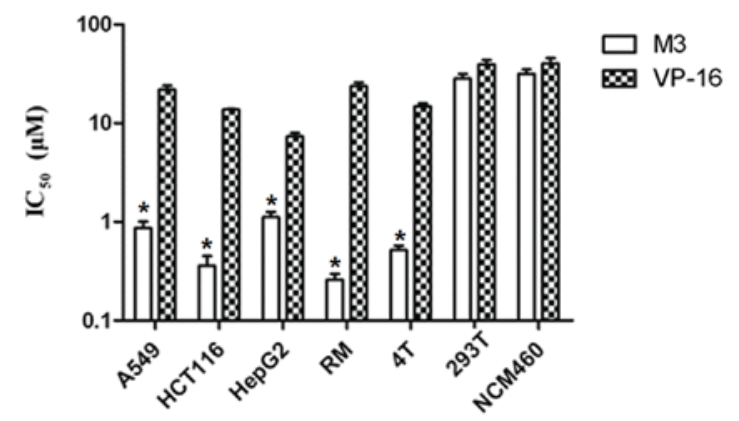

Figure 1. (A) Structure of M3. (B) Structure of VP-16. (C) Inhibitory effect of VP-16 and M3 in a number of cell lines. $\mathrm{IC}_{50}$ values were determined by MTT assay. Data are presented as the mean \pm standard error of the mean and experiment was conducted in triplicate. ${ }^{*} \mathrm{P}<0.05$ vs. the same cell line treated with VP-16. M3, 4-O-(2',3',4'-tri-O-methyl- $\beta$-D-xylopyranosyl) diphyllin; $\mathrm{IC}_{50}$, half maximal inhibitory concentration.

were harvested, washed with PBS, centrifuged with $300 \mathrm{x} \mathrm{g}$ for $5 \mathrm{~min}$ at $4^{\circ} \mathrm{C}$ and stained with $100 \mu \mathrm{l}$ Annexin-V-FLUOS labeling solution. Cells were incubated for $10-15 \mathrm{~min}$ at $15-25^{\circ} \mathrm{C}$ and then analyzed using a flow cytometer.

Western blot analysis. HCT116 cells treated with different compounds (M3, Toxol, and Colchicine) for $72 \mathrm{~h}$ were lysed and cellular lysates were harvested. Lysates were centrifuged at $300 \mathrm{x} \mathrm{g}$, at $4^{\circ} \mathrm{C}$ for $20 \mathrm{~min}$. Protein were extracted with protein extraction buffer (cat. no. KGP250; Nanjing KeyGen Biotech Co., Ltd.), Protein samples were determined by bicinchoninic acid assay, and 25 ul protein were added per lane, then separated by $10 \%$ SDS-PAGE and transferred to nitrocellulose membranes. Following blocking with 5\% skimmed milk for $2 \mathrm{~h}$ at room temperature, the membranes were washed three times with TBS buffer. The membranes were then incubated with primary antibodies at a dilution of 1:100 against $\beta$-actin, cleaved caspase-3, caspase- 3 and cleaved poly(ADP-ribose) polymerase (PARP), polymerized tubulin (pellet) and soluble tubulin (supernatant) (cat. no. 4970, 9664, 9662, 9532, 2144 and 2146, respectively) Cell Signaling Technology, Inc., Danvers, MA, USA) at a dilution of 1:100 overnight at $4^{\circ} \mathrm{C}$. Membranes were washed three times with a buffer containing TBS and Tween-20, and incubated with peroxidase-conjugated secondary anti-mouse or anti-rabbit antibodies (cat. no. A-11061; Thermo Fisher Scientific, Inc.) at a dilution of 1:1,000 for $2 \mathrm{~h}$. Protein bands were visualized by film exposure with an enhanced chemiluminescence kit (Nanjing KeyGen Biotech Co., Ltd.) using Quantity One 4.6.6 software (Bio-Rad Laboratories, Inc., Hercules, CA, USA) was used.

Immunocytochemistry. Immunocytochemistry was performed as described previously $(12,13,15)$. Briefly, HCT116 cells $\left(1 \times 10^{4}\right.$ cells/well) were plated in 24-well plates and grown for 
Table I. $\mathrm{IC}_{50}$ values of M3 and VP-16 in various cell lines.

Mean $\mathrm{IC}_{50}$ value \pm standard error of the mean

\begin{tabular}{lrrrrrrr}
\cline { 2 - 7 } Reagent & \multicolumn{1}{c}{ A549 } & HCT116 & HepG2 & RM & 4T & $293 \mathrm{~T}$ & NCM460 \\
\hline M3 & $0.87 \pm 0.14$ & $0.08 \pm 0.03$ & $1.12 \pm 0.14$ & $0.26 \pm 0.04$ & $0.52 \pm 0.05$ & $28.50 \pm 3.11$ & $31.80 \pm 3.13$ \\
VP-16 & $21.90 \pm 2.14$ & $13.80 \pm 0.15$ & $7.34 \pm 0.61$ & $23.80 \pm 2.14$ & $14.80 \pm 1.12$ & $39.50 \pm 3.98$ & $40.50 \pm 5.12$ \\
\hline
\end{tabular}

M3, 4-O-(2',3',4'-tri-O-methyl- $\beta$-D-xylopyranosyl) diphyllin; $\mathrm{IC}_{50}$, half maximal inhibitory concentration.

$24 \mathrm{~h}$ at $37^{\circ} \mathrm{C}$. Cells were treated with M3 $(0.125$ and $0.25 \mu \mathrm{M})$ at $4^{\circ} \mathrm{C}$ for $24 \mathrm{~h}$. Cells were washed and incubated with anti- $\alpha$-tubulin monoclonal antibodies (dilution, 1:100) overnight at $4^{\circ} \mathrm{C}$, followed by incubation with Alexa Fluor 555-conjugated secondary antibodies (dilution, 1:100; cat. no. A-21422; Thermo Fisher Scientific, Inc.) in the dark for 2 h. Subsequently, $300 \mu \mathrm{l}$ of $5 \mu \mathrm{g} / \mathrm{ml}$ Hoechst 33342 solution was added to each well and stained samples were incubated in the dark for $10 \mathrm{~min}$ at room temperature. Microtubules were observed and images were captured using a fluorescence microscope (magnification, $\mathrm{x} 400$ ).

Tubulin polymerization assay. Tubulin polymerization assays were performed as described previously (16-18). The CytoDYNAMIX Screen 03 Tubulin Polymerization assay kit was purchased from Cytoskeleton, Inc. (Denver, CO, USA). Briefly, HCT116 cells $\left(1 \times 10^{6}\right.$ cells $\left./ \mathrm{ml}\right)$ were seeded into a $100-\mathrm{mm}$ culture dish and cultured in Dulbecco's modified Eagle's medium containing $0.1 \%$ dimethylsulfoxide with taxol $(10 \mu \mathrm{M})$, colchicine $(5 \mu \mathrm{M})$ or $\mathrm{M} 3(10,20$ or $40 \mu \mathrm{M})$ at $37^{\circ} \mathrm{C}$ for $24 \mathrm{~h}$. Absorbance was measured at a wavelength of $340 \mathrm{~nm}$ and was recorded at $37^{\circ} \mathrm{C}$ every min for $60 \mathrm{~min}$.

Statistical analysis. Data are presented as the mean \pm standard error of the mean. All statistical analyses were performed using SPSS software (version 16.0; SPSS, Inc., Chicago, IL, USA). Student's t-test was performed for paired observations and one-way analysis of variance with Fisher's least significant difference test was performed for multiple comparisons. $\mathrm{P}<0.05$ was considered to indicate a statistically significant difference.

\section{Results}

M3 inhibits proliferation of cancer cell lines. Five cancer cell lines from various solid tumors, plus 293T cells and a normal colonic epithelial cell line NCM460 cells, were used to determine the effects of M3 (Fig. 1A) on cell proliferation using MTT assays. VP-16 (Fig. 1B) was selected as a control. The $\mathrm{IC}_{50}$ values determined are presented in Table $\mathrm{I}$. The mean $\mathrm{IC}_{50}$ values for M3 and VP-16 in all cell lines were $0.32 \mu \mathrm{M}$ (range, $0.08-1.12 \mu \mathrm{M}$ ) and $15.7 \mu \mathrm{M}$ (range, 4.1-25.2 $\mu \mathrm{M}$ ), respectively. This indicated that M3 exhibits a higher antiproliferative effect against tumorigenic cell lines compared with VP-16 $(\mathrm{P}<0.05$; Fig. 1C). M3 inhibited proliferation of the taxol-resistant A549 cell line, with an $\mathrm{IC}_{50}$ value of $0.87 \mu \mathrm{M}$, which was markedly lower compared with the $\mathrm{IC}_{50}$ value of VP-16 $(21.9 \mu \mathrm{M})$. The $\mathrm{IC}_{50}$ value for M3 in the 293T cells was $28.5 \mu \mathrm{M}$, which was lower compared with the $\mathrm{IC}_{50}$ value of VP-16 $(39.5 \mu \mathrm{M})$. In addition, the $\mathrm{IC}_{50}$ value of $\mathrm{M} 3$ in the human colon carcinoma HCT116 cell line was $0.08 \mu \mathrm{M}$, which was markedly lower compared with that of VP-16 $(13.8 \mu \mathrm{M})$. Therefore, in order to further study the role of M3 in colon cancer, the current study selected HCT116 cells to investigate the initial mechanism of M3 in cancer cells, in order to further study the role of M3 in colon cancer.

M3 induces apoptosis in HCT116 cells. Annexin-V-FLUOS staining and flow cytometry were performed to investigate the effect of M3 on the apoptosis of HCT116 cells (19-21). As demonstrated in Fig. 2A, the early and late apoptotic cell populations increased in response to M3 in a concentration-dependent manner. The proportions of the early and late apoptotic cells increased from 8.1 and $29.5 \%$, respectively, at $0.03 \mu \mathrm{M}$ of $\mathrm{M} 3$ to 11.3 and $65.1 \%$, respectively, at $0.25 \mu \mathrm{M}$ of $\mathrm{M} 3$. By contrast, the proportions of early and late apoptotic cells were 9.2 and $29.5 \%$, respectively, when the cells were treated with $10 \mu \mathrm{M}$ VP-16. It was then identified that the levels of cleaved caspase-3 and cleaved PARP increased upon exposure to M3 in a concentration-dependent manner, while expression level of non-cleaved capase-3 decreased (Fig. 2B and C). This suggests that M3-induced apoptosis may be mediated by a caspase-dependent pathway. Furthermore, the proliferation rate was inhibited by M3 (Fig. 2D).

In addition, fluorescence staining was used to investigate morphological changes in HCT116 cells following treatment with different concentrations of M3 for $24 \mathrm{~h}$. Cells were treated with M3, stained with Hoechst 33342 and visualized using a fluorescence microscope. Morphological changes that reflected apoptosis, including chromatin condensation and fragmentation of the nucleus, were observed in HCT116 cells treated with M3 (0.125 and 0.25 $\mu \mathrm{M}$; Fig. 2E).

M3 inhibits microtubule polymerization in HCT116 cells. Immunocytochemistry, according to previously published techniques (22-24), was used to investigate the effect of M3 on microtubule networks in HCT116 cells. As demonstrated in Fig. 3, the microtubule network exhibited a normal arrangement and organization in untreated HCT116 cells. However, notable microtubule disassembly was identified in HCT116 cells treated with $0.125-0.5 \mu \mathrm{M}$ M3 for $24 \mathrm{~h}$.

Next, the effects of M3 on tubulin polymerization in vitro were compared with a tubulin depolymerizing reagent, colchichine, and a tubulin polymerizing agent, taxol. As demonstrated in Fig. 4A, following treatment with M3 for 3,000 sec, the absorbance of tubulin decreased compared with that of the control group, which was treated with DMEM and 0.1\% DMSO. This 
A
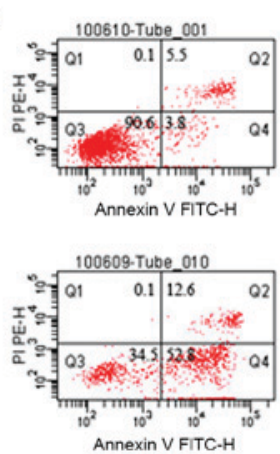

D

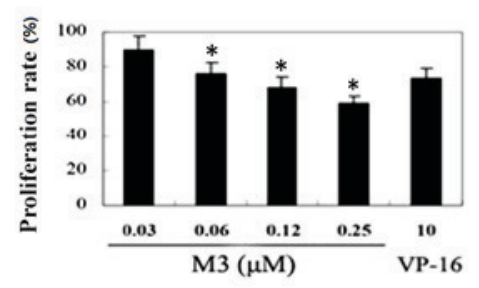

B
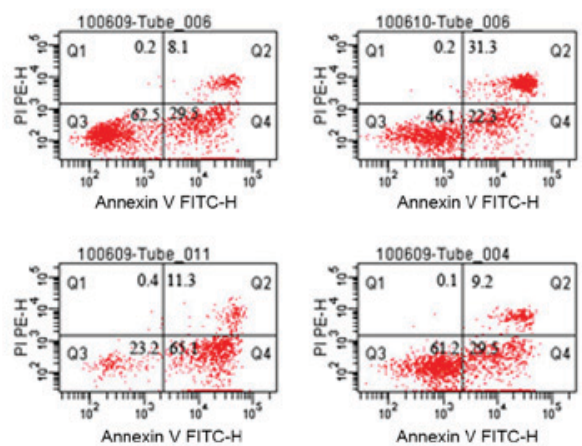

E
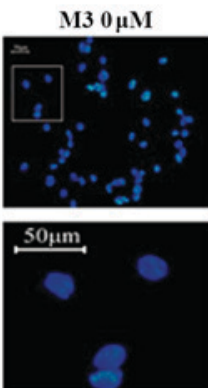
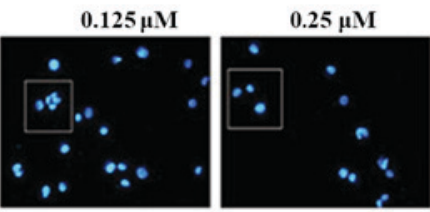

$\mathrm{M} 3(\mu \mathrm{M})$
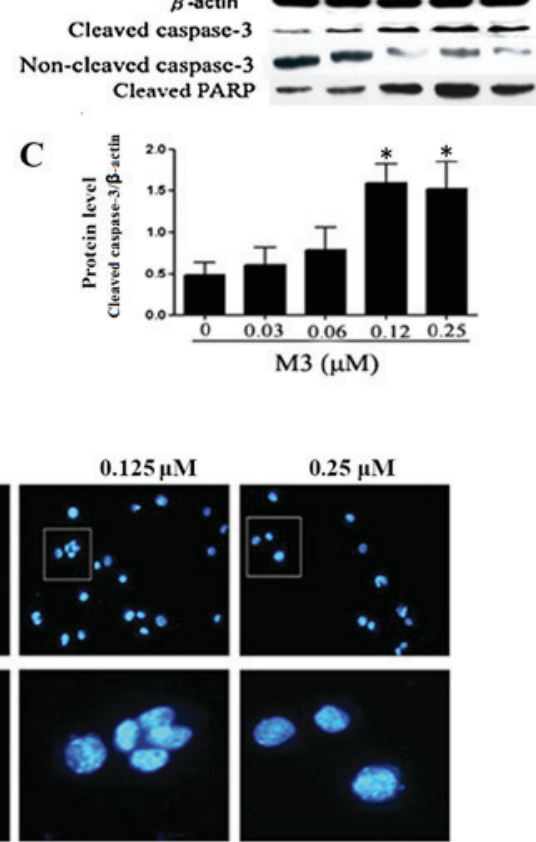

Figure 2. M3 induces apoptosis of HCT116 cells in a concentration-dependent manner. Q1 consists of dead cells, Q2 consists of late apoptotic cells, Q3 consists of early apoptotic cells, Q4 consists of non-apoptotic cells. (A) Apoptosis of HCT116 cells treated with M3 for $72 \mathrm{~h}$. Annexin -V-FLUOS staining was used to detect apoptotic HCT116 cells. (B) Effect of M3 on the expression of cleaved caspase-3 and cleaved PARP in HCT116 cells. Cells were treated with various concentrations of $\mathrm{M} 3(0.03,0.06,0.12$ and $0.25 \mu \mathrm{M})$ for $72 \mathrm{~h}$ and then examined by western blot analysis. $\beta$-actin was used for normalization. (C) Statistic analysis of densitometry. Data are presented as the mean \pm standard error of the mean from three independent experiments. " $\mathrm{P}<0.05$ vs. cells treated with $0 \mu \mathrm{M}$ M3. (D) Proliferation rate of HCT166 cells treated with various concentrations of M3 and VP-16. Data are presented as the mean \pm standard error of the mean from three independent experiments. "P $<0.05$ vs. cells treated with $0.03 \mu \mathrm{M}$ M3. (E) Nuclear morphology of HCT116 cells following treatment with various concentrations of M3. HCT116 cells were treated with different concentrations of M3 $(0,0.125$ and $0.25 \mu \mathrm{M})$ for $24 \mathrm{~h}$. Representative images of cells stained with Hoechst 33342, observed using a fluorescence microscope, are presented. Magnification, x200. PARP, poly(ADP-ribose) polymerase; M3, 4-O-(2',3',4'-tr i-O-methyl- $\beta$-D-xylopyranosyl) diphyllin; FITC, fluorescein isothiocyanate; PI, propidium iodide.

$\mathrm{M} 3(\mu \mathrm{M})$

0

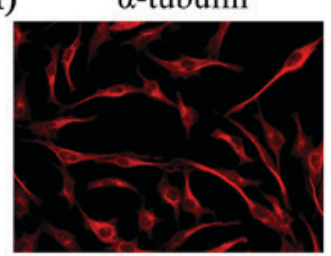

0.125

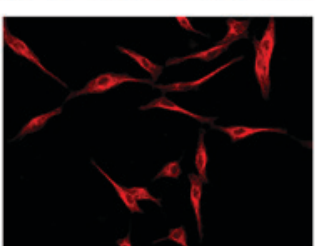

0.25
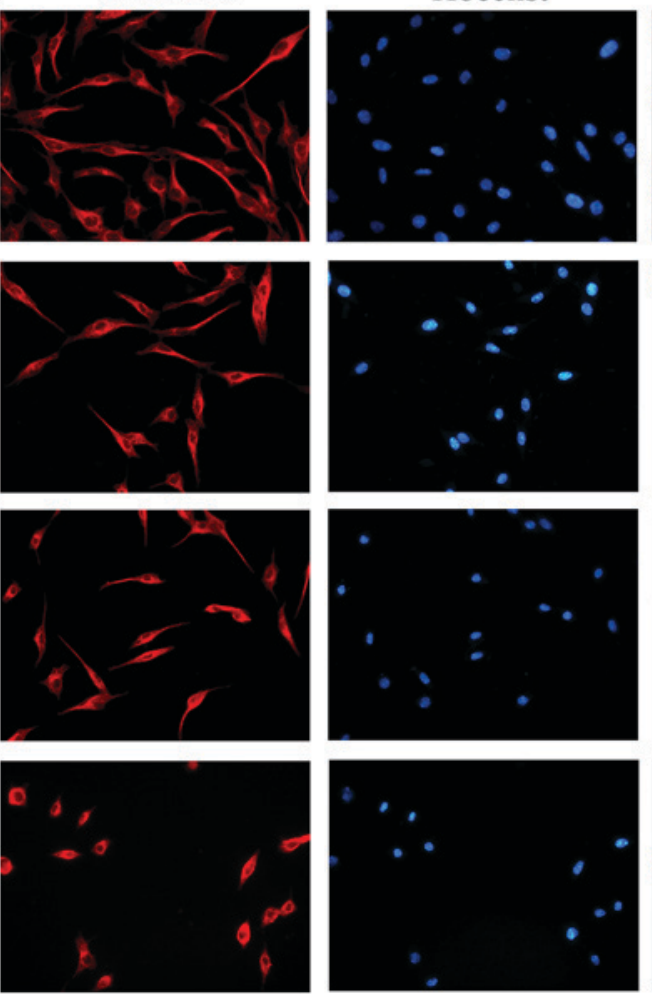

Merge
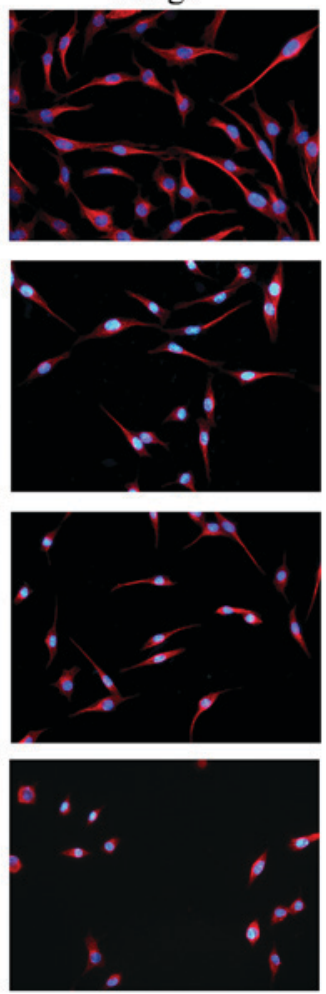

Figure 3. Effect of M3 on the organization of microtubules in HCT116 cells. HCT116 cells were treated with different concentrations of M3 $(0,0.125,0.25$ and $0.50 \mu \mathrm{M})$ for $24 \mathrm{~h}$. Microtubules were observed by fluorescence microscopy. Magnification, x400. M3, 4-O-(2',3',4'-tri-O-methyl- $\beta$-D-xylopyranosyl) diphyllin . 
A
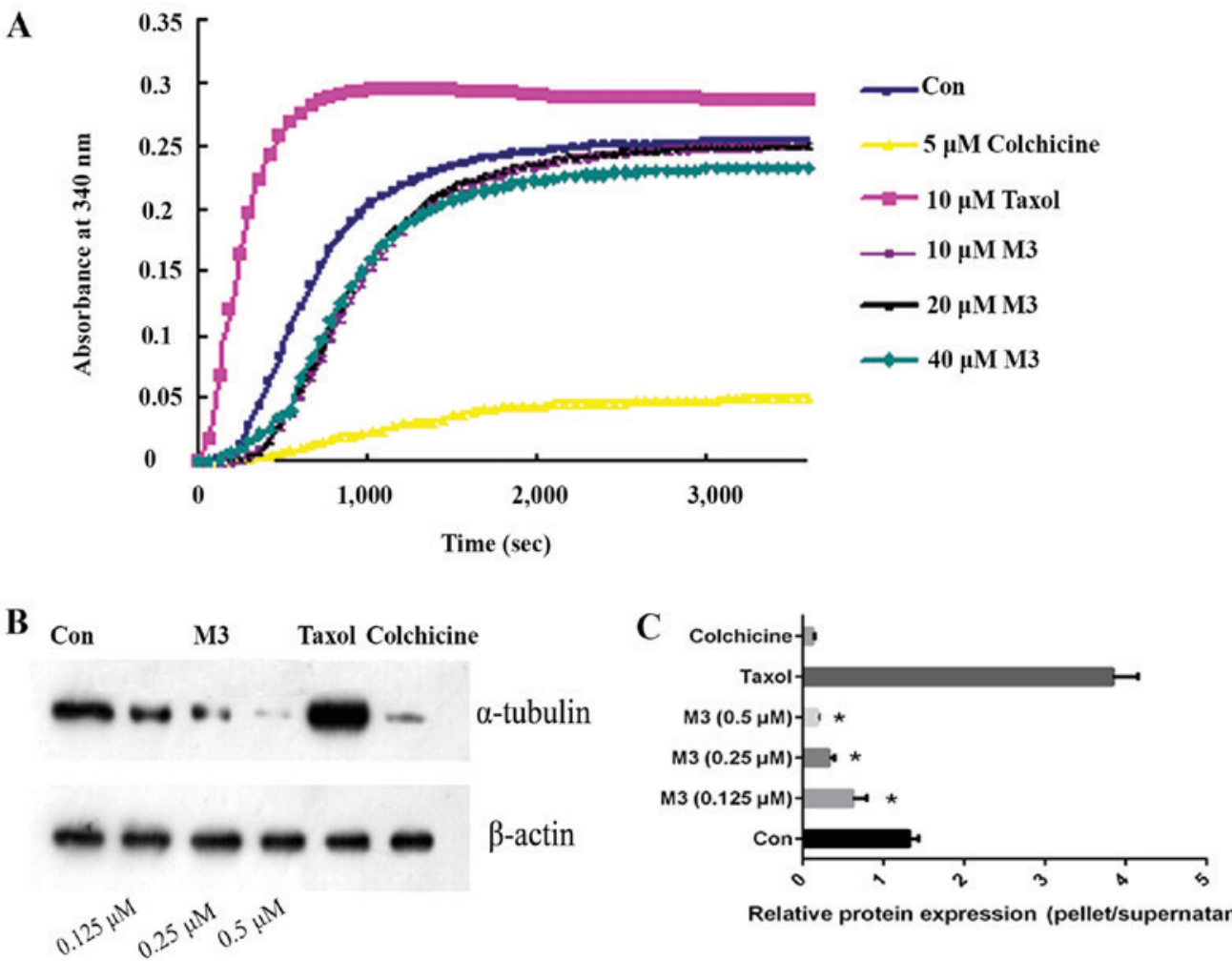

Relative protein expression (pellet/supernatant)

Figure 4. Effect of M3 on microtubule assembly in HCT116 cells. (A) M3 inhibits microtubule assembly in vitro. Microtubule assembly assays were performed using a Tubulin Polymerization assay kit. Cells $\left(1 \times 10^{6}\right.$ cells $\left./ \mathrm{ml}\right)$ were incubated with taxol $(10 \mu \mathrm{M})$, colchicine $(5 \mu \mathrm{M})$ or $\mathrm{M} 3(10,20$ or $40 \mu \mathrm{M})$. Cells in the control group were incubated in Dulbecco's modified Eagle's medium containing $0.1 \%$ dimethylsulfoxide. Absorbance at $340 \mathrm{~nm}$ was recorded at $37^{\circ} \mathrm{C}$ every min for 60 min. (B) M3 inhibits microtubule assembly in HCT116 cells. HCT116 cells were treated with taxol $(0.5 \mu \mathrm{M})$, colchicine $(0.5 \mu \mathrm{M})$ or M3 $(0.125$, 0.25 or $0.5 \mu \mathrm{M}$ ) for $24 \mathrm{~h}$. The expression of $\alpha$-tubulin was detected by western blot analysis. (C) The relative protein expression level of polymerized $\alpha$-tubulin. ${ }^{\prime 2} \mathrm{P}<0.05$ vs. con. M3, 4-O-(2',3',4'-tri-O-methyl- $\beta$-D-xylopyranosyl) diphyllin; con, control.

indicated that treatment with M3 was associated with a decrease in the rate of microtubule assembly; however, M3 exhibited a markedly weaker effect compared with colchicine.

Additionally, the protein expression levels of polymerized tubulin (pellet) and soluble tubulin (supernatant) were observed following treatment of HCT116 cells with M3, colchicine and taxol. As demonstrated in Fig. 4B and C, the expression level of polymerized $\alpha$-tubulin decreased significantly in cells treated with M3 compared with the control group. It was identified that treatment with M3 was associated with a decrease in the expression level of polymerized $\alpha$-tubulin in a concentration-dependent manner. This suggests that M3 may promote microtubule depolymerization in HCT116 cells.

\section{Discussion}

The majority of cancer types are characterized by uncontrolled cell proliferation, inhibited cell differentiation and decreased contact inhibition, which provides tumor cells with the capacity to metastasize and invade local tissues (23). Several diphyllin glycosides can inhibit cancer cell proliferation; however, to the best of our knowledge, the molecular targets of diphyllin glycosides are unknown $(4,9,10)$. Previous studies have identified that, at high concentrations, certain diphyllin glycosides exhibit inhibitory effects on DNA topoisomerase II and microtubule polymerization (6,7). Therefore, the current study investigated the biological activities of M3, a diphyllin glycoside, in cancer cells.
M3 was identified to inhibit the growth of a number of cancer cell lines in vitro, while exerting a much weaker effect in the 293T cell line and the normal colon cell line, NCM460. This suggests that M3 may potentially be used as a chemotherapeutic agent. However, further studies are required to investigate the effect of $\mathrm{M} 3$ on other normal colon cell lines and to clarify the mechanisms underlying the antiproliferation effect of M3 in vitro.

Microtubule-targeting agents bind to microtubules and either promote or inhibit tubulin assembly, thereby interfering with cell division and cell proliferation. These agents can exhibit marked antitumor effects and can be categorized as tubulin polymerization-promoting, tubulin polymerization-inhibiting or tubulin-depolymerizing agents $(11,15,20,23)$. Taxol, serve an important role in cancer therapy; however, its side effects include bone marrow suppression, neurotoxicity and multidrug resistance, which limits their clinical applications (20-22). The current study identified that M3 exhibits similar effects on cellular microtubule assembly in HCT116 cells compared with the tubulin-depolymerizing reagent colchicine. This suggests that M3 may be used as a microtubule inhibitor in cancer treatment.

Microtubule inhibitors can also induce apoptosis via a number of different mechanisms. Paclitaxel can activate and regulate numerous genes associated with apoptosis, including Fas, Fas ligand, p53, p21, the Bcl family and the caspase family $(23,24)$. Apoptosis is characterized by morphological changes, including cell shrinkage, cytoplasmic blebbing, chromatin condensation, DNA fragmentation and caspase 
activation $(11,24)$. The current study revealed that M3 induces apoptosis of HCT116 cells at a lower concentration compared with VP-16. In addition, an increased level of caspase-3 was detected in M3-treated HCT166 cells compared with control cells, which indicates that M3 may induce apoptosis in a caspase-3-dependent manner.

In conclusion, the current study demonstrated that M3 inhibits the proliferation of HCT116 cells and induces apoptosis in a caspase-3-dependent manner. This provides a basic understanding of the anticancer effect of M3 in HCT116 cells. However, to further investigate its potential use as an anticancer agent, the precise underlying mechanism of M3 should be investigated in future in vitro and in vivo studies.

\section{Acknowledgements}

Not applicable.

\section{Funding}

The current study was supported by the Natural Science Foundation of Jiangsu Province (grant no. BK20171157).

\section{Availability of data and materials}

All data generated or analyzed during this study are included in this published article.

\section{Authors' contributions}

HC, TZ conducted the study. WS collected all the data and analyzed. YZ provided the M3 and designed the study. SW and PL were responsible for the design and conduction of the study. All authors have read and approved the final version of the manuscript.

\section{Ethics approval and consent to participate}

Not applicable.

\section{Patient consent for publication}

Not applicable.

\section{Competing interests}

The authors declare that they have no competing interests.

\section{References}

1. Weymouth-Wilson AC: The role of carbohydrates in biologically active natural products. Nat Prod Rep 14: 99-110, 1997.

2. Seeberger PH and Werz DB: Automated synthesis of oligosaccharides as a basis for drug discovery. Nat Rev Drug Discov 4 751-763, 2005.

3. Gui M, Shi DK, Huang M, Zhao Y, Sun QM, Zhang J, Chen Q, Feng JM, Liu CH, Li M, et al: D11, a novel glycosylated diphyllin derivative, exhibits potent anticancer activity by targeting topoisomerase II $\alpha$. Invest New Drugs 29: 800-810, 2011.

4. Shi DK, Zhang W, Ding N, Li M and Li YX: Design, synthesis and biological evaluation of novel glycosylated diphyllin derivatives as topoisomerase II inhibitors. Eur J Med Chem 47: 424-431, 2012.
5. Pradheepkumar CP, Panneerselvam $\mathrm{N}$ and Shanmugam G: Cleistanthin A causes DNA strand breaks and induces apoptosis in cultured cells. Mutat Res 464: 185-193, 2000.

6. You Y: Podophyllotoxin derivatives: Current synthetic approaches for new anticancer agents. Curr Pharm Des 11: 1695-1717, 2005.

7. Meenakshi J and Shanmugam G: Cleistanthin A, a diphyllin glycoside from Cleistanthus collinus, is cytotoxic to PHA-stimulted (proliferating) human lymphocytes. Drug Dev Res 51: 187-190, 2000

8. Hemmati S, Schneider B, Schmidt TJ, Federolf K, Alfermann AW and Fuss E: Justicidin B 7-hydroxylase, a cytochrome P450 monooxygenase from cell cultures of Linum perenne Himmelszelt involved in the biosynthesis of diphyllin. Phytochemistry 68: 2736-2743, 2007

9. Zhang ZT, Ma J, Zhu L and Zhao Y: Synthesis and identification of cytotoxic diphyllin glycosides as vacuolar H(+)-ATPase inhibitors. Euro J Med Chem 82: 466-471, 2014.

10. Zhao Y, Ni C, Zhang Y and Zhu L: Synthesis and bioevaluation of diphyllin glycosides as novel anticancer agents. Arch. Pharm (Weinheim) 345: 622-628, 2012.

11. Tuchinda P, Kumkao A, Pohmakotr M, Sophasan S, Santisuk T and Reutrakul V: Cytotoxic arylnaphthalide lignan glycoside from the aerial parts of Phyllanthus taxodiifolius. Plant Med 72: 60-62, 2006.

12. Chen C, Wang CC, Wang Z, Geng WY, Xu H, Song XM and Luo DQ: Cytotoxic activity of a synthetic deoxypodophyllotoxin derivative with an opened D-ring. J Asian Nat Prod Res 18: 486-494, 2016.

13. Kandil S, Wymant JM, Kariuki BM, Jones AT, McGuigan C and Westwell AD: Novel cis-selective and non-epimerisable C3 hydroxy azapodophyllotoxins targeting microtubules in cancer cells. Eur J Med Chem 3: 311-325, 2016.

14. López-Terrada D, Cheung SW, Finegold MJ and Knowles BB: Hep G2 is a hepatoblastoma-derived cell line. Hum Pathol 40: $1512-1515,2009$.

15. Jaing JD, Davis AS, Middleton K, Ling YH, Perez-Soler R, Holland JF and Bekesi JG: 3-(Iodoacetamido)-benzoylurea: A novel cancericidal tubulin ligand that inhibits microtubule polymerization, phosphorylates bcl-2 and induces apoptosis in tumor cells. Cancer Res 58: 5389-5395, 1998.

16. Davis AS, Jiang JD, Middleton KM, Wang Y, Weisz I, Ling YH and Bekesi JG: Novel suicide ligands of tubulin arrest cancer cells in S-phase. Neoplasia 1: 498-507, 1999.

17. Hyman AA, Middleton K, Centola M, Mitchison TJ and Carbon J: Microtubule-motor activity of a yeast centromere-binding protein complex. Nature 359: 533-536, 1992.

18. Shin JW, Son JY, Kang JK, Han SH, Cho CK and Son CG: Trichosanthes kirilowii tuber extract induces G2/M phase arrest via inhibition of tubulin polymerization in HepG2 cells. J Ethnopharmacol 115: 209-216, 2008.

19. Chen FH, Zhang LB, Qiang L, Yang Z, Wu T, Zou MJ, Tao L, You QD, Li ZY, Yang Y and Guo QL: Reactive oxygen species-mitochondria pathway involved in LYG-202-induced apoptosis in human hepatocellular carcinoma HepG(2) cells. Cancer Lett 296: 96-105, 2010.

20. Solier S and Pommier Y: MDC1 cleavage by caspase-3: A novel mechanism for inactivating the DNA damage response during apoptosis. Cancer Res 71: 906-913, 2011.

21. Hande KR, Hagey A, Berlin J, Cai Y, Meek K, Kobayashi H, Lockhart AC, Medina D, Sosman J, Gordon GB and Rothenberg ML: The pharmacokinetics and safety of ABT-751, a novel, orally bioavailable sulfonamide antimitotic agent: Results of a phase 1 study. Clin Cancer Res 12: 2834-2840, 2006.

22. Kuo CC, Hsieh HP, Pan WY, Chen CP, Liou JP, Lee SJ, Chang YL, Chen LT, Chen CT and Chang JY: BPR0L075, a novel synthetic indole compound with antimitotic activity in human cancer cells, exerts effective antitumoral activity in vivo. Cancer Res 64: 4621-4628, 2004.

23. Benaka Prasad SB, Vinaya K, Ananda Kumar CS, Swarup S and Rangappa KS: Synthesis of novel 6-fluoro-3-(4-piperidinyl)1,2-benzisoxazole derivatives as antiproliferative agents: A structure-activity relationship study. Invest New Drugs 27: 534-542, 2009.

24. Kroemer G, Dallaporta B and Resche-Rigon M: The mitochondrial death/life regulator in apoptosis and necrosis. Annu Rev Physiol 60: 619-642, 1998.

This work is licensed under a Creative Commons Attribution-NonCommercial-NoDerivatives 4.0 International (CC BY-NC-ND 4.0) License. 